\title{
Testing the Use of the Integrated Model in Designing the Management Information Systems by Using the Mathematical Probability Theories
}

\author{
Mohammad M M Abu Omar \& Khairul Anuar Abdullah \\ Limkokwing University of Creative Technology, Malaysia
}

\begin{abstract}
The integrated model is a new model that is recently developed to decrease from the classical approach weaknesses and problems in building the management information systems (MIS's) that are used to solve the management problems in the practical life. The use of this integrated model needs to be tested, to prove how efficiently and successfully the model works. To achieving this objective, this paper uses the mathematical probability theories to implement an internal test of the integrated model work before using it in the practical life. The paper uses the qualitative research method in its methodologies.
\end{abstract}

Keywords-Integrated Model; Management Information System; MIS; Classical Approach; Information System Life Cycle; ISLC; Simple Random Sampling; Probability Theory

\section{INTRODUCTION}

\section{A. What is the classical approach}

Classical or (traditional) approach is one of the information systems methodologies that are used to build the information systems. One of these information systems is a management information system (MIS), which is a computerbased system that is used in solving management problems [12],[13].

Classical approach has the variety of approaches according to its use; since it adopts the information system life cycle (ISLC) on its work. There are many different ISLC models, but each one of them consists of a series of defined steps or phases, which should occur when building the MIS [10].

These five main steps or stages are:

1) Planning Stage: it is the first stage in the information system life cycle. The responsibilities of this stage are:

- Defining the problem and collecting the required information about the problem that the system will solve it [2], [3].

- Determining the user's requirements, which the developed system will solve.. [2],[3].

- Determining the estimated budget and time to accomplish the system [2], [3].

- Suggesting a solution or list of solutions to the problem [2], [3].

2) Analysis Stage: it is the second stage in the information system life cycle. In this stage, the system analyzer will study each solution in the list of the suggested solutions that is obtained from the previous stage (planning stage) and then choose the best solution [2],[3].

3) Design Stage: it is the third stage in the information system life cycle. Here, the designer's team will provide all the necessary design requirements such as input screens, output screens, reports, database and system algorithms [2], [3].

4) Development Stage: it is the fourth stage in the information system life cycle. Here the system will be programmed and operated [2],[3].

5) Test and Maintenance Stage: it is the fifth (final) stage in the information system life cycle. Here, the system will be tested to verify whether it includes errors or if it needs improvements to be better and effective in achieving the users' requirements [2],[3].

\section{B. What is the drawback of the classical approach}

The information system life cycle of the classical approach (ISLC) consists of five main stages that are: planning, analysis, design, implementation, and maintenance or test stages. The classical approach uses these stages in its work in building the management information systems that will be used to solve the management problems. The weakness and problem of the classical approach arises from the permanent use of all of these five stages in all cases; because there are many cases that actually need to use some of these stages but not to all of them, and as a result the classical approach suffers from the weakness and problem in consuming more time and additional cost when it is used to build the management information systems (MIS's) in order to solve the management problems [1],[2],[3].

\section{What is the integrated model, why there is need for this model}

The integrated model is a recently developed model by Mohammad Abu Omar and Khairul Anuar Abdullah [1], which uses the classical approach as one of the systems development methodologies to build the management information systems (MIS's) which are used to solve the management problems.

The integrated model aims to improve the weakness of the classical approach that consumes additional time and cost. The integrated model has accomplished its mission by through the following actions: 
a) Finding a new classification of the management problems, that may be solved by building the MIS's.

b) Developing new sub- approaches from the information system life cycle (ISLC) that is adopted by classical approach. These sub-approaches don't use the all stages of the (ISLC) of the classical approach, but only the necessary ones.

c) Implementing a compatibility between the newly developed sub-approaches and the different types of the management problems, to achieve suitable and effective use of the sub-approaches in solving the management problems by building the MIS's.

The integrated model will avoid the classical approach in the permanent use of the all stages in its life cycle, by choosing a suitable sub-approach to a suitable management problem.

\section{THE BACKGROUND OF THE INTEGRATED MODEL STRUCTURE AND WORK}

The integrated model develops a new classification of the management problems, as follows [1]:

1) The first category management problems, which include the following problems:

\section{a) First order management problem}

b) Second order management problem.

2) The second category management problems, which includes the following problems:

\section{a) First level management problem \\ b) Second level management problem}

3) The combined management problems, which include the following problems:
a) First combined management problem
b) Second combined management problem
c) Third combined management problem
d) Fourth combined management problem

Meanwhile, the integrated model develops the subapproaches from the information system life cycle (ISLC) that is adopted by classical approach. These sub- approaches are:

1) MIS new approach (1)

2) MIS new approach (2)

3) MIS new approach (3)

And finally, the integrated model appoints a suitable subapproach for solving the related management problem, as in the following procedures [1]:

- The first procedure: (MIS new approach (1) for solving the first order management problem):

The first order management problem has a direct solution; which is clear, and it is usually one. One need only to collect the required information about this problem in order to implement it, and therefore there is no need to find multiple solutions to the problem and having to choose the best solution. This means that there is no need to consume more time, effort and cost in using the analysis stage, which is the second stage in the information system life cycle that is adopted by classical approach [1],[3].

In this case, the integrated model develops a new subapproach which is defined as: MIS new approach (1), which skips using the analyses stage in building the management information system by using the classical approach [1],[3].

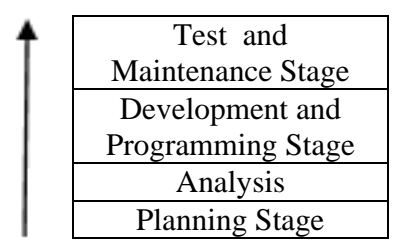

Fig. 1. The MIS New Approach (1)

Thus, the skipping of the analysis stage by the MIS approach (1) will decrease from the consumption of additional time and cost through using the classical approach in designing the MIS's to solve the management problems.

- The second procedure: (MIS new approach (2) for solving the first level management problem):

The first level management problem needs software, which can be found sin off-the shelf software packages. This means that management problem doesn't need to build and develop new software, but it can use off-the shelf software packages which can be purchased directly in the markets [1], [2].

According to the information system life cycle (ISLC) adopted by the classical approach, and explained in the introduction of this paper, we will find that the building of the computer program (software), which the management information system (MIS) will use to solve the management problems, is related directly with the third stage (Design Stage) in the information system life cycle. This is because the building of the computer program (software) includes the building of: algorithms, database, input and output screens, reports,....etc, and these are the responsibilities of the (Design Stage) in the information system life cycle [1],[2].

In this case, the integrated model develops a new subapproach which is defined as: MIS new approach (2), which skips the use of the design stage in building the management information system by using the classical approach [1],[3].

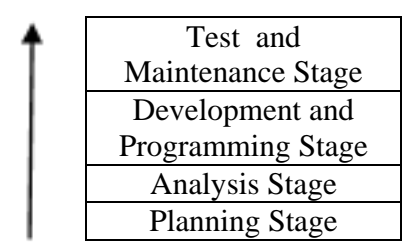

Fig. 2. The MIS New Approach (2)

Thus, the skipping of the design stage by the MIS approach (2) will decrease from the consumption of additional time and cost through using the classical approach in designing the MIS's to solve the management problems.

- The third procedure: (MIS new approach (3) for solving the first combined management problem): 
The first combined management problem is formed by the combination of the first order management problem and the first level management problem [1], [2].

The first combined management problem is a first order management problem and a first level management problem at same time. Consequently, this problem inherits the skipping of the analysis stage from the first order management problem, and also inherits the skipping of the design stage from the first level management problem. Meanwhile, the integrated model develops a new sub-approach which is defined as: MIS new approach (3), which skips the using of the both design and analysis stages in building the management information system by using the classical approach [1],[3].

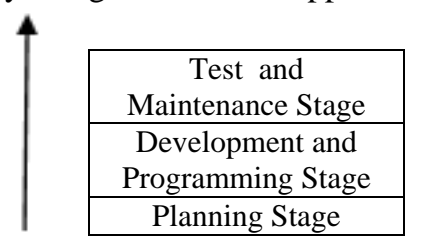

Fig. 3. The MIS New Approach (3)

Thus, the skipping of the analysis and design stages by the MIS approach (3) will decrease more from the consumption of additional time and cost through using the classical approach in designing the MIS's to solve the management problems.

\section{- The fourth procedure:}

The integrated model uses the whole information system life cycle (ISLC) that is adopted by classical approach without skipping any stage in the other management problems, which are defined in the management problems classification and which aren't used in the previous three procedures. These problems are:

- Second order management problem

- Second level management problem

- Fourth combined management problem

The nature and properties of these management problems make the integrated model use all the stages of the (ISLC) of the classical approach under the name of: the MIS classical approach [1], [2], [3].

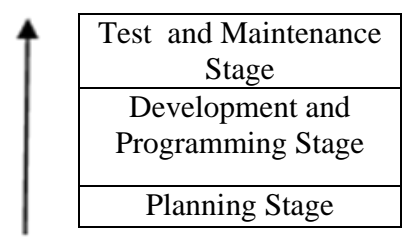

Fig. 4. The MIS Classical Approach

The following figure shows the integrated model structure and work [1]:

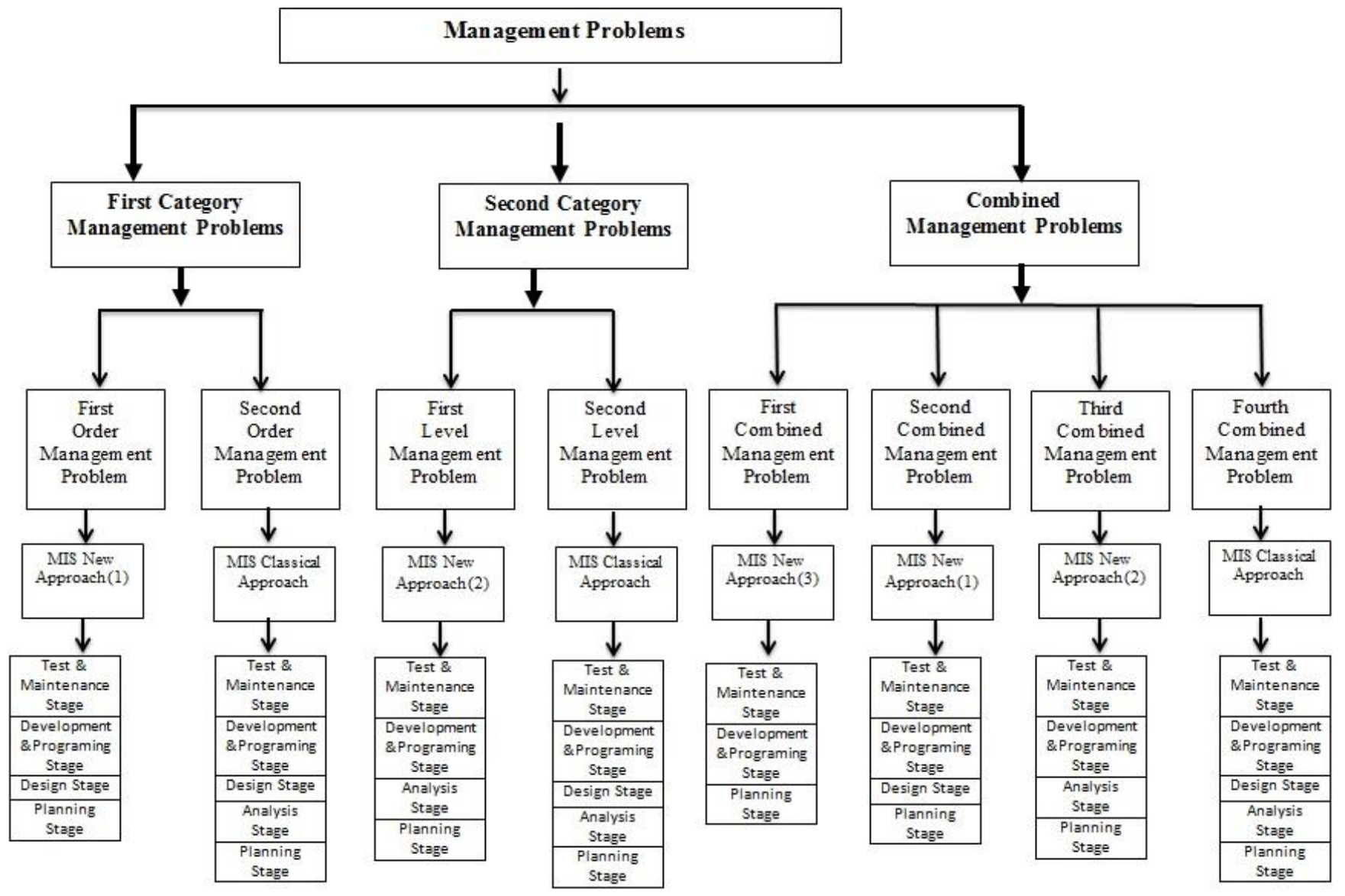

Fig. 5. The Integrated Model: Structure and Work 


\section{WhY TESTING OF THE INTEGRATED MODEL}

According to the previous procedures of the integrated model, some of the integrated model's sub- approaches achieve the integrated model goal in preventing the classical approach from the consumption of additional time and cost while building the MIS's, because these sub- approaches skip some stages in the ISLC of the classical approach which are not necessary in building the MIS's, at the same time, there are some cases that the integrated model can't skip any stage in the ISLC of the classical approach while building the MIS's. From here, the integrated model needs to the test, in order to see the overall evaluation of its work, to determine if it is valid or not in achieving its goal in solving the classical approach problem which is the additional time and cost consumed while building the MIS.

\section{A. Testing of the Integrated Model}

As it is mentioned in this paper, the integrated model classifies the management problems as in the following:

\begin{tabular}{|c|c|}
\hline First Category Management Problems \\
\hline$>$ & First Order Management Problems \\
\hline$>$ & Second Order Management Problems \\
\hline Second Category Management Problems \\
\hline$>$ & First Level Management Problems \\
\hline$>$ & Second Level Management Problems \\
\hline Combined Management Problems \\
\hline$>$ First Combined Management Problems \\
\hline$>$ Second Combined Management Problems \\
\hline$>$ Third Combined Management Problems \\
\hline$>$ Fourth Combined Management Problems \\
\hline
\end{tabular}

Fig. 6. The management problems types in the integrated model

Now, the research will determine the management problems which will be solved without consuming additional time and cost, by using one of the developed MIS subapproaches, as in the fig 7 .

This research uses the mathematical probability theories to implement the testing of the integrated model. This testing acts as internal test of the integrated model before using it in the practical life.

The testing procedure includes two tests, which are:

1) Test (A): The Percentage Law Test

2) Test (B): The Simple Random Sampling (SRS) Probability Method Test

\begin{tabular}{|c|c|c|c|}
\hline No & $\begin{array}{l}\text { Management } \\
\text { Problem Type }\end{array}$ & $\begin{array}{l}\text { MIS } \\
\text { Developed } \\
\text { Approach }\end{array}$ & $\begin{array}{l}\text { Saving Time \& } \\
\text { Cost During the } \\
\text { building of MIS to } \\
\text { Solve the } \\
\text { Management } \\
\text { Problem } \\
\end{array}$ \\
\hline 1 & $\begin{array}{l}\text { First Order } \\
\text { Management } \\
\text { Problem } \\
\end{array}$ & $\begin{array}{l}\text { MIS Approach } \\
\text { (1) }\end{array}$ & $\checkmark$ \\
\hline 2 & $\begin{array}{l}\text { Second Order } \\
\text { Management } \\
\text { Problem }\end{array}$ & $\begin{array}{l}\text { MIS Classical } \\
\text { Approach }\end{array}$ & \\
\hline 3 & $\begin{array}{l}\text { First Level } \\
\text { Management } \\
\text { Problem } \\
\end{array}$ & $\begin{array}{l}\text { MIS Approach } \\
\text { (2) }\end{array}$ & $\checkmark$ \\
\hline 4 & $\begin{array}{l}\text { Second Level } \\
\text { Management } \\
\text { Problem }\end{array}$ & $\begin{array}{l}\text { MIS Classical } \\
\text { Approach }\end{array}$ & \\
\hline 5 & $\begin{array}{l}\text { First Combined } \\
\text { Management } \\
\text { Problem }\end{array}$ & $\begin{array}{l}\text { MIS Approach } \\
\text { (3) }\end{array}$ & $\checkmark$ \\
\hline 6 & $\begin{array}{l}\text { Second Combined } \\
\text { Management } \\
\text { Problem }\end{array}$ & $\begin{array}{l}\text { MIS Approach } \\
\text { (1) }\end{array}$ & $\checkmark$ \\
\hline 7 & $\begin{array}{l}\text { Third Combined } \\
\text { Management } \\
\text { Problem } \\
\end{array}$ & $\begin{array}{l}\text { MIS Approach } \\
\text { (2) }\end{array}$ & $\checkmark$ \\
\hline 8 & $\begin{array}{l}\text { Fourth Combined } \\
\text { Management } \\
\text { Problem }\end{array}$ & $\begin{array}{l}\text { MIS Classical } \\
\text { Approach }\end{array}$ & \\
\hline
\end{tabular}

Fig. 7. The harmonization between the MIS sub-approaches and all types of management problems in the integrated model

\section{B. Test (A): The Percentage Law Test}

It is a general test which aims to measure the percentage of management problems which will be solved through the integrated model without consuming additional time and cost:

By returning to the figures: $6 \& 7$, we will obtain the following:

- The number of all management problems types in the integrated model $=(8)$.

- The number of management problems types which will be solved by the integrated model without consuming additional time and cost $=$ [The number of management problems types which will be solved by using one of these developed MIS sub-approaches: MIS (1), MIS (2), MIS (3)] = (5).

- The number of management problems types which will be solved by the integrated model without saving time and cost $=$ [The number of the management problems types which will be solved by using the MIS classical approach $]=(3)$. 
Now, test (A) will use the percentage law, as in the following:

Number of All Management Problems Types in the Integrated Model ( which equals 8 )

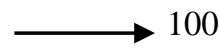

Number of management problems types which will be solved by the integrated model without consuming additional time and cost ( which equals 5 )

Then, the result of applying the previous percentage law is follows:

The value of $X=\frac{5 * 100}{8}$

Thus, the percentage of $X=\frac{5 * 100}{8} \%$

Hence, we can find the following:

a) The percentage of the management problems which will be solved by the integrated model without consuming additional time and cost, will be calculated as follows:

$$
\frac{5 * 100}{8} \%=62.5 \%
$$

b) The percentage of the management problems which will be solved without saving time and cost is:

$$
100 \%-62.5 \%=37.5 \%
$$

1) Analysis of the Test (A) Results:

Test (A) gives positive results of using the integrated model, since the results of test (A) shows that $(62.5 \%)$ of the management problems in the integrated model will be solved without consuming additional time and cost, while $(37.5 \%)$ of the management problems will be solved without saving time and cost, thus, test (A) confirms the success of using the integrated model.

The results of the test (A) are clarified through the following chart:

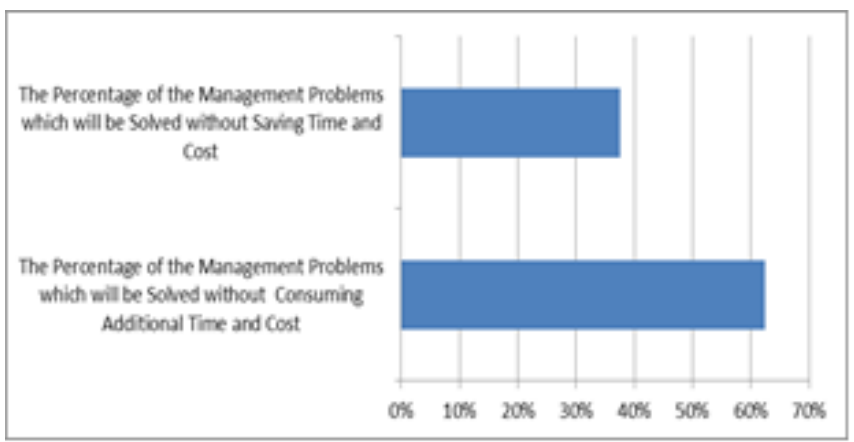

Fig. 8. The test (A) results

\section{Test (B): The Simple Random Sampling (SRS) Probability Method Test}

Test (B), is a determined test and it aims to measure the expected probability of using each developed sub-approach: [MIS approach (1), MIS approach (2), MIS approach (3)] which will solve the management problems without consuming additional time and cost. Accordingly, the expected probability of using the MIS classical approach that will solve the management problems without saving time and cost will also be measured. and Finally, the comparison between the two results will be created, in order to prove the validity or invalidity, of using the integrated model.

This test is implemented by using the simple random sampling (SRS) probability method, as in the following experiment (Test (B) Experiment):

\section{a) Test (B) Experiment}

The test (B) experiment describes the integrated model as in the following figure:

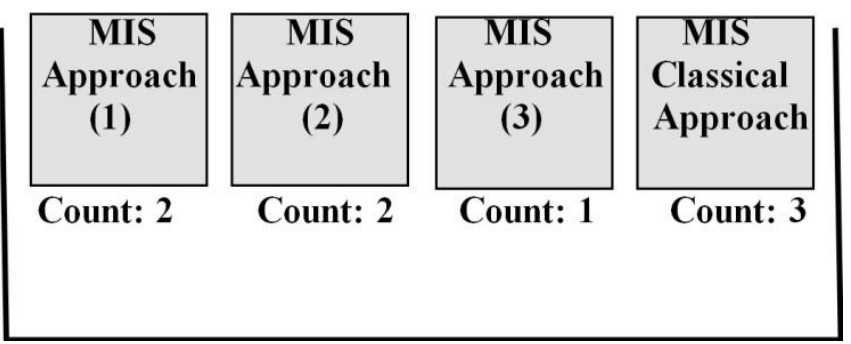

Fig. 9. Test (B) experiment

\section{b) Test (B) Experiment Ingredients:}

According to the simple random sampling probability method (SRS), the test (B) experiment ingredients will be as follows:

- The Sample Space ( $\mathbf{\Omega})$ : it is the set of all possible outcomes of the experiment.

In test (B) experiment, the sample space $(\Omega)$ will be as follows:

$$
\begin{aligned}
& \Omega=\{\text { MIS Approach (1), MIS Approach (2), } \\
&\text { MIS Approach (3), MIS Classical Approach }\} \\
& \text { - The Number of Sample Space Elements: }
\end{aligned}
$$

As it is shown in figure (9), the test (B) experiment includes:

- Two from MIS approach (1).

- Two from MIS approach (2).

- One from MIS approach (3).

- Three from MIS classical approach.

So, the number of all $(\Omega)$ elements, is (8) elements in the test (B) experiment.

\section{- The Event:}

The event (E) is a set of outcomes of an experiment (a subset of the sample space) to which a probability is assigned [20].

In test (B) experiment, the events will be as follows:

E1: $\{$ MIS approach (1) \}.

E2: $\{$ MIS approach (2) \}.

E3: \{MIS approach (3)\}.

E4: \{Classical MIS approach\}. 


\section{- The Probability Theory:}

The simple random sampling (SRS) probability method defines the probability of an event $\mathrm{E} \quad[\mathrm{P}(\mathrm{E})]$, as the number of outcomes favorable to the event, divided by the total number of outcomes [19]:

$P(E)=\frac{\text { Number of Elements of } E}{\text { Total Number of Elements in } \Omega}=\frac{\text { Favorable Outcomes }}{\text { Total Outcomes }}$

Each element in the sample space $(\Omega)$ has an equal probability of selection and each combination of elements has an equal probability of selection.

Now, test (B) will apply the probability theory of the simple random sampling method to all experiment events, and thus the probability of using of each sub-approach in the integrated model will be calculated, as follows:

- Probability of using the MIS approach (1) is indicated as: $\mathrm{P}$ (MIS approach (1)), and then:

$$
\mathrm{P}(\mathrm{MIS} \text { approach }(1))=\frac{2}{8}=0.25
$$

-Probability of using the MIS approach (2) is indicated as: $\mathrm{P}$ (MIS approach (2)), and then:

$$
\mathrm{P}(\mathrm{MIS} \text { approach }(2))=\frac{2}{8}=0.25
$$

-Probability of using the MIS approach (3) is indicated as: $\mathrm{P}$ (MIS approach (3)), and then:

$$
\mathrm{P}(\mathrm{MIS} \text { approach }(3))=\frac{1}{8}=0.125
$$

-Probability of using the MIS classical approach is indicated as: P (MIS classical approach), and then:

$$
\mathrm{P}(\text { MIS classical approach })=\frac{3}{8}=0.375
$$

\section{c) Analysis of the Test (B) Results}

The previous results of test (B) experiment show a high probability of using the MIS developed approaches which will limit the consumption of additional time and cost in building the MIS's in order to solve the management problems. These approaches and the probabilities of using each one of them are as follows:

\begin{tabular}{|l|l|}
\hline The MIS Developed Approach & Probability of the Using \\
\hline MIS approach (1) & 0.25 \\
\hline MIS approach (2) & 0.25 \\
\hline MIS approach (3) & 0.125 \\
\hline \multicolumn{2}{|c|}{ Total of the Probabilities: 0.625} \\
\hline
\end{tabular}

Fig. 10. The positive results of test (B)

The probability of using the MIS classical approach that will not limit the consumption of additional time and cost in building the MIS's in order to solve the management problems, is (0.375). Thus, the results of test (B) experiment prove the validity and success of using the integrated model.

The results of the test (B) experiment are clarified through the following chart:

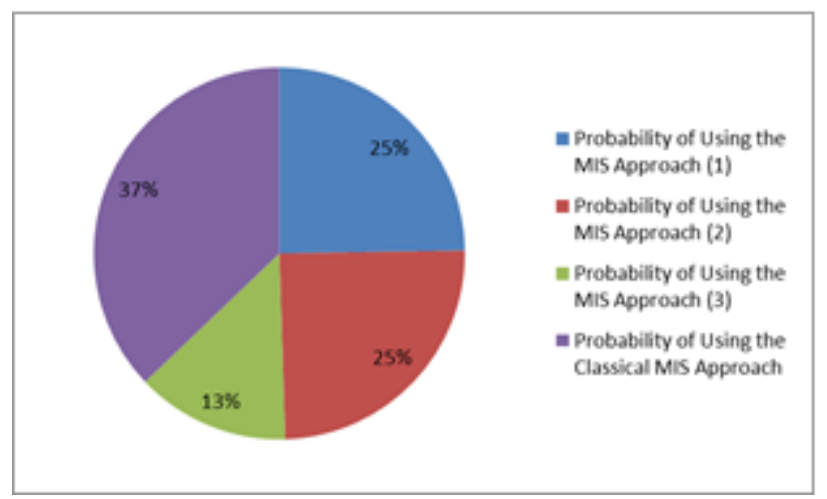

Fig. 11. Test (B) Results

\section{CONCLUSION}

This paper uses the mathematical probability theories to test the validity of the integrated model in achieving its work and mission in limiting the consumption of additional time and cost through using of the classical approach in building the MIS's in order to solve the management problems. The paper implements two main internal tests that are test (A) and test (B), and the tests' results confirm the success of the integrated model in achieving its work and mission, since the tests' results show that the integrated model can solve $62.5 \%$ from the management problems without consuming additional time and cost, while $37.5 \%$ of the management problems will be solved without the saving of time and cost.

\section{FUTURE WORK}

After the success of the integrated model in the internal test that implemented in this paper, the integrated model needs now an external test in the practical use. This test will increase the confidence of system-developers in the integrated model.

\section{REFERENCES}

[1] Mohammad M M Abu Omar, Khairul Anuar Abdullah "Developing a New Integrated Model to Improve the Using of Classical Approach in Designing Management Information Systems" , International Journal of Advanced Computer Science and Applications- IJACSA, September 2015, Volume 6 - Issue 9.

[2] Mohammad M M Abu Omar, "A New Approach to Increase the Efficiency of Classical Approach in Designing Management Information Systems(MIS's)", International Journal of Research in Computer and Communication Technology-IJRCCT, November 2014, Volume 3Issue 11.

[3] Mohammed M M Abu Omar, "Developing New Methods in Designing Management Information Systems by Using Classical Approach to Solve Management Problems", International Journal of Computer Applications-IJCA, September 2014, Volume 101.

[4] Mathias Riechert, "Research Information Standardization as a Wicked Problem: Possible Consequences for the Standardization", in Proceedings of the International Conference of Current Research Information Systems, at Rome, 2014, Volume 12.

[5] Samson Yusuf Dauda, Jongsu Lee, "Technology adoption: A conjoint analysis of consumers' preference on future online banking services", Elsevier Journal of Information Systems, 2015, Volume 53.

[6] Ram L Kumar, Antonis C Stylianou, "A process model for analyzing and managing flexibility in information system", European Journal of Information Systems, 2013. 
[7] Abubucker Samsudeen Shaffi, Mohaned Al-Obaidy "Analysis and Comparative Study of Traditional and Web Information Systems Development Methodology (WISDM) Towards Web Development Applications", International Journal of Emerging Technology and Advanced Engineering-IJETAE, November,2013, Volume 3-Issue 11.

[8] Valdis Vizulis, Edgars Diebelis, "Self-Testing Approach and Testing Tools", Journal of University of Latvia, 2012, Volume 787.

[9] Lionel Briand, Yvan Labiche, "A UML-Based Approach to System Testing", Journal of Carleton University, 2002, Version 4.

[10] Hardcastel, E., Business Information Systems, Ventus Publishing, 2008.

[11] Langer, A. M., Analysis and Design of Information Systems, Springer, 3rd Edition, 2008.

[12] Laudon, Kenneth C., and Laudon, Jane P., Management Information Systems, Prentice -Hall International, 9th Edition, 2006.

[13] Laudon, Kenneth C., Essentials of Management Information Systems, Prentice -Hall International, 6th Edition, 2005.

[14] Lejk, M. and Deeks, D., An Introduction to Systems Analysis Techniques, 2nd Ed., Pearson Education Limited, 2002.

[15] Satzinger, J., Systems Analysis and Design, 2nd ed., Thomson Learning, 2002.

[16] Dennis, A. et al, Systems Analysis and Design: An- Object-Oriented Approach with UML, John Wiley \&Sons Inc., 2002.

[17] Maciaszek, A., Requirments Analysis and System Design, Developing Information Systems with UML, Addison-Wesley, 2001.

[18] Griffin, R. W., Management, 7th Edition, Houghton Mifflin, 2001.
[19] Ash, R. B., Basic Probability Theory, 1st Edition, Dover Publications Inc., New York, 2008.

[20] http://www.mathgoodies.com/

[21] . Ziya Aktas, A., Structured Analysis and Design of Information Systems, Prentice- Hall, 1987.

[22] Mayes, T. R. and Shank, T. M., Financial Analysis with Microsoft Excel, South-Western College Publishing, $6^{\text {th }}$ Edition, 2011.

[23] Gitman,L.J., Principle of Managerial Finance, Pearson Education Inc., 2003.

[24] Christian Nielsen, Morten Lund (Eds.), The Basics of Business Models, bookboon.com., 2nd Edition, 2014

\section{ABOUT THE Authors}

Mohammad M M Abu Omar is currently pursuing his $\mathrm{PhD}$ in Information Systems at Limkokwing University of Creative Technology, Malaysia. Abu Omar has published many papers related to the area of information technology and management, in impact international peer reviewed journals. He is a member in many technical committees and editorial boards in international peer reviewed journals. Abu Omar is also a member of the scientific committees of many international conferences throughout the world including: Switzerland, Poland, Malaysia, Japan, and India.

Dr. Khairul Anuar Abdullah is currently a faculty member in the Post Graduate Center of Limkokwing University of Creative Ttechnology, Malaysia. He received his PhD from the University of Newcastle, Australia., $\mathrm{He}$ is a supervisor of many masters and $\mathrm{PhD}$ thesis in Limkokwing University of Creative Technology. 